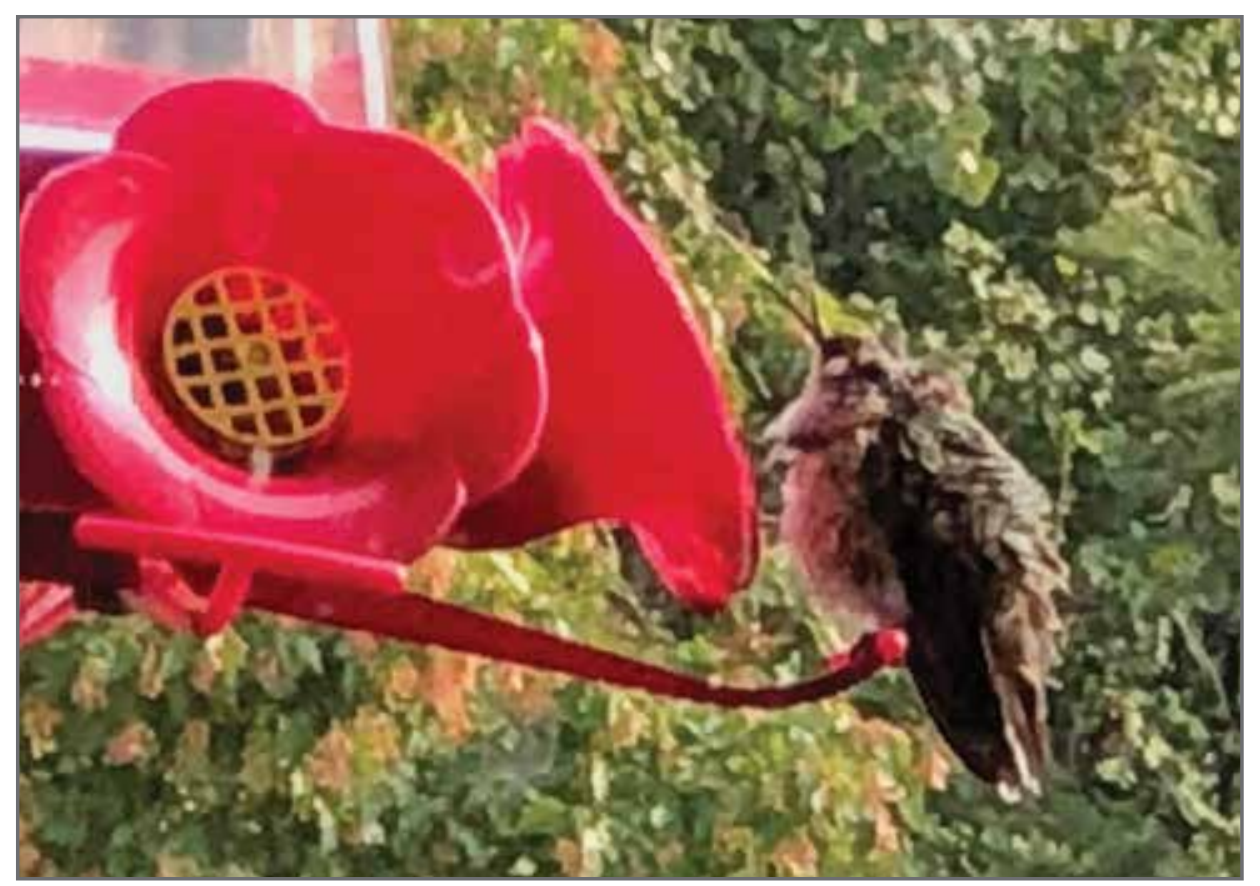

FIGURE 1. Cropped original cellphone photograph of the Ruby-throated hummingbird. Photo credit: T. Pulles

\section{RUBY-THROATED HUMMINGBIRD WITH A DEFORMED BILL}

\section{Ron Jensen}

1027 King Crescent

Saskatoon, SK S7K 0N9

rjes@shaw.ca

On August 18, 2018, a banding host forwarded me a cellphone picture of a dishevelled Rubythroated Hummingbird (Archilochus colubris) at his feeder, north of Blaine Lake, SK, asking what I thought (Figure 1). In reply, I suggested the hummingbird just needed some of the sugar water to fortify its 37 hummingbirds in four hours at this site.

However, I had very different thoughts and impressions when Phil Taylor and I arrived at the host's home to band hummingbirds. The first hummingbird to appear at the trap was the very same constitution. I've banded as many as
Ruby-throated Hummingbird

(RTHU) that the banding host had photographed. This banding site has, over the past four years, supported a concentration of RTHUs in August — presumably migrating or getting fattened up to migrate south to their wintering area.

It was immediately obvious that this hummingbird had a wonky bill
(Figures 2, 3). The upper mandible was shorter and upturned, whereas the lower mandible was straight, measuring $12.6 \mathrm{~mm}$ and shorter than expected (Table 1). The tongue extended well beyond the end of the mandibles where the tongue would normally reside. It should be totally hidden unless exposed to feed on nectar or sugar water. To feed on nectar or at a sugar water feeder, a hummingbird opens its mandibles slightly permitting the tongue to glide out and back into the mandible and mouth and be swallowed, delivering the sugar water/nectar to the crop.

It was no surprise that this hummingbird was at the lower end of 'normal' weight, at $2.6 \mathrm{~g}$ (Table 1). While in hand, I offered it the opportunity to drink a sugar water solution from an open, small container. It drank eagerly. While the bird drank, it was possible to observe the area between the eyes pulsating. Satisfying its hunger, the bird weakly flew off. It returned to a feeder to feed five more times over the four hours of this day's banding session. It was also recaptured a second time to ensure our original observations were correct. This RTHU gained strength in its flight. It was encouraging to observe.

This hummingbird had an undersized mandible and was underweight compared to hatch year (juvenile) RTHU males for 2015-2018 (Table 1).

\section{TABLE 1. Mandible length and weight ranges and means for Hatch Year (HY) RTHU for 2015-20181.}

\begin{tabular}{|c|c|c|c|c|c|}
\hline YEAR & $2015^{*}$ & 2016 & 2017 & 2018 & THIS RTHU \\
\hline NUMBER & 26 & 34 & 32 & 44 & 1 \\
\hline MANDIBLE LENGTH (MM) & & & & & 12.6 \\
\hline RANGE & $14.6-18.6$ & $13.5-17.5$ & $14.2-17.5$ & $13.8-17.5$ & \\
\hline MEAN & 16.4 & 15.3 & 15.5 & 15.5 & \\
\hline \multicolumn{6}{|l|}{ WEIGHT (G) } \\
\hline RANGE & $2.8-4.4$ & $2.8-4.9$ & $2.8-4.2$ & $2.9-4.4$ & 2.6 \\
\hline MEAN & 3.2 & 3.4 & 3.3 & 3.3 & \\
\hline
\end{tabular}

*First full summer of banding mandible measurements may be inaccurate due to lack of measuring experience. 


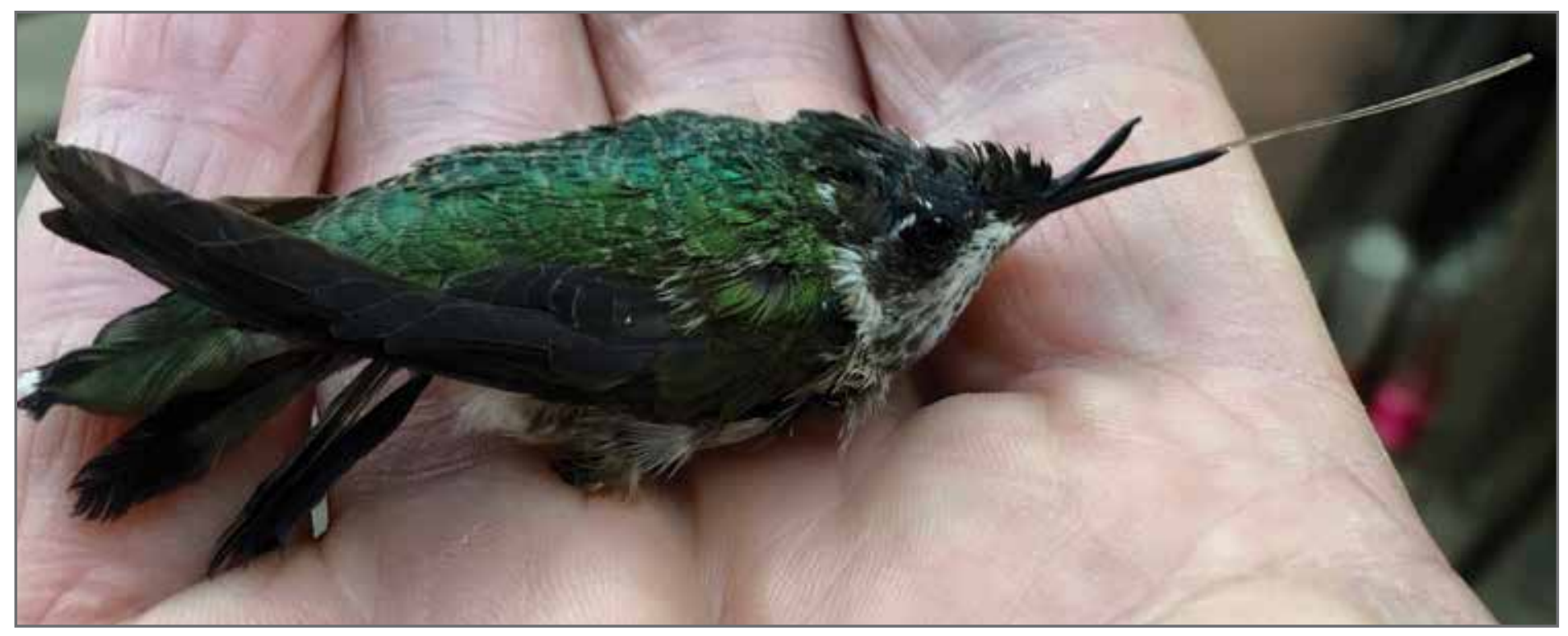

FIGURE 2. A dishevelled, weak RTHU with a deformed bill. Photo credit: P. Taylor

Figures $4 a$ and $4 b$ show a 'normal' looking HY RTHU male. A 'normal' HY RTHU appears to have a forehead or rounding between the eyes. The deformed bill HY RHTU (Figure 3) appears to be flat between the eyes, giving the impression that this $\mathrm{HY}$ RTHU possibly lacks a forehead. This view is supported by observations of the skin and feathers above the eyes pulsating as the hummingbird eagerly drank sugar water provided in a small container.

I posted a picture of the hummingbird with a deformed bill on a private website for hummingbird banders, HumBand, which is dedicated to the exchange of information among permitted hummingbird banders, asking

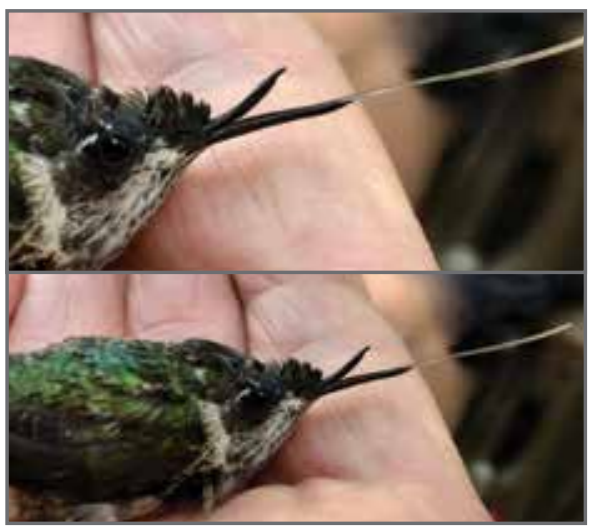

FIGURE 3. Extreme close-up of bill and head of the hummingbird (left) and close-up of the same bird, a hatch year male. Photo credit: P. Taylor whether other banders had encountered similar birds.

A follow-up post to my original pictures posted on August 21 on HumBand appeared on August 30. The HumBand post showed pictures (Figure 5) of a RTHU with a twisted bill from Alabama. It looks very similar to a bird observed and captured in Michigan, later, in early September by Allen Chartier (Figure 6).

Both RTHUs (Figures 5 and 6) appear to have twisted mandibles in contrast to the hummingbird that stars in this article. Note that the forehead area, above the eyes, is similar to the 'normal' RTHU photograph shown in Figures 4 and 4 a. This leads me - personal observation - to suggest that

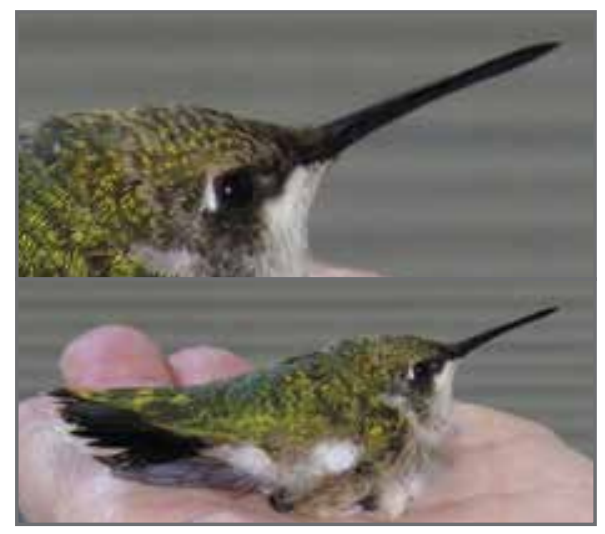

FIGURE 4A. Close up of a "normal" HY male RTHU. FIGURE 4B. A "normal" HY male RTHU. Photo credit: R. Jensen disease may not be the cause for the deformed mandibles of the Saskatchewan RTHU.

The following is excerpted comments from HumBand by experienced, permitted hummingbird banders:

"I've seen tons of healed bill fractures, a handful of bills with bits missing, and a couple of dislocations, but never anything like your photo. I suspect it's a birth defect, not a disease, and that we don't see more of them because they don't survive long after fledging."

- Lanny Chambers, hummingbird bander in lowa; www.humminbirds.net

"Both mandibles seem to be smooth, which more likely indicates either a genetic problem or perhaps an injury to the bill when the bird was a very new nestling."

- Dr. Bill. Hilton Jr., Hilton Pond Center for Piedmont Naturalist; www.rubythroat.org

"I see maybe 5-10 birds a year with bill deformities, a couple as bad as the Alabama bird pictured, but most with obvious bends/injuries to their bills. Most seem to be coping well with their injuries; even the few I've seen this year with mis-aligned bills have weighed normal or a little heavy (3.0-3.5 grams)." 


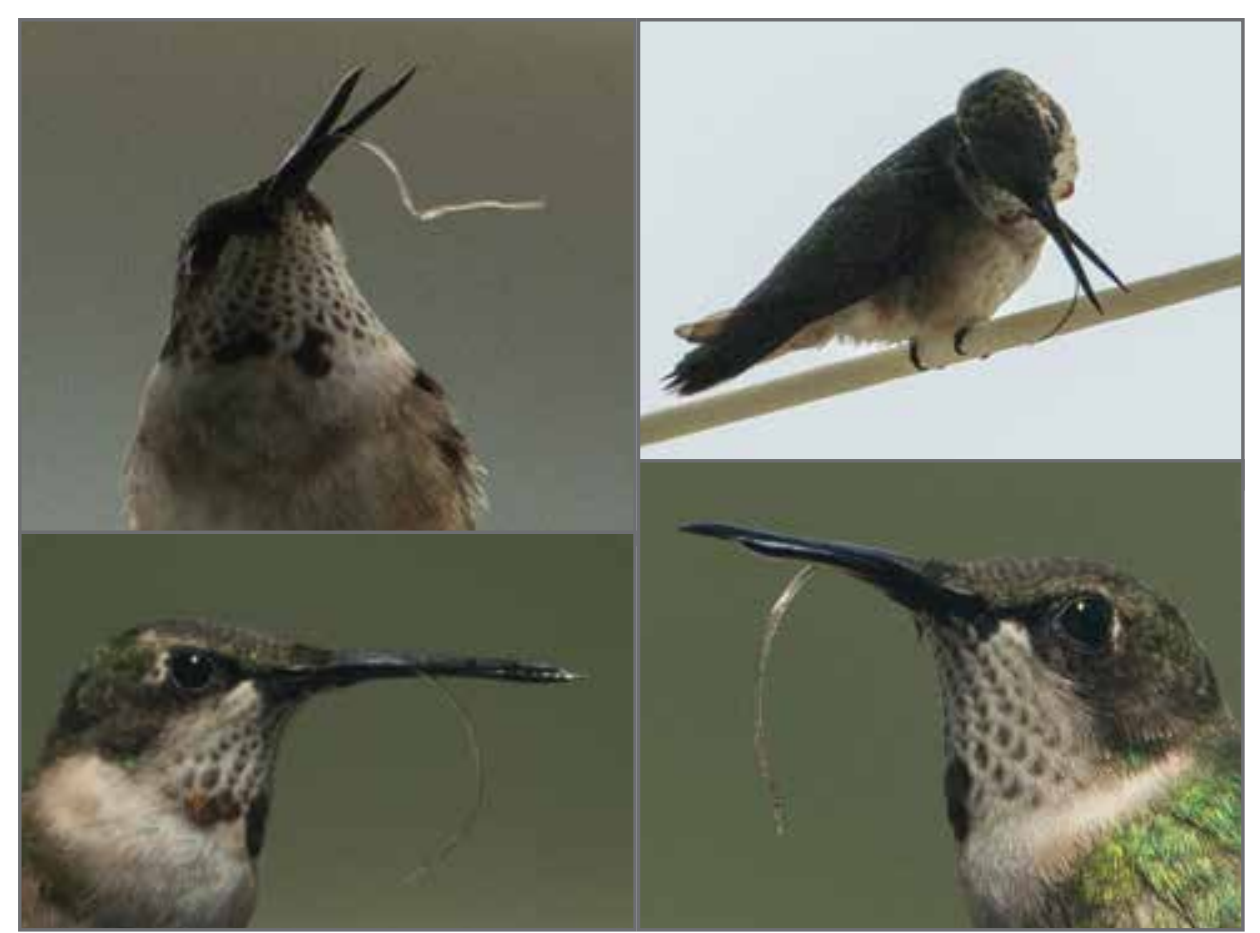

FIGURE 5. Photographs of Alabama Ruby-throated Hummingbird, a hatch year male. Photo credit: Franklin Chalk

- Cathie Hutcheson, bands over 5,000 Ruby-throated Hummingbirds annually in southern Illinois since 2000. Cathie has banded about 86,000 RHTU.

"... On September 6, I captured and banded an AHY [after hatch yearadult], male Ruby-throat with mandibles that were crossed in both axes, and with the tongue protruding and apparently of limited function. I have included a composite photo here (sorry for the poor cell-phone camera quality). Of particular note is that the bird was very fat, and weighed 4.77 grams. I find this difficult to explain. The bird surely has difficulty feeding, so how did it get so fat? Does the virus that Scott told us about cause bill deformities to manifest quickly?" - Allen T. Chartier, master bander in Michigan; http://mihummingbirdguy. blogspot.com (look at Great Lakes HummerNet for banding details and reports)

"The photo appears to show the maxilla and lower mandible deformed but in line with each other - is that correct? [yes] I rather think it's not avian keratin disorder, the bill deformity syndrome associated mostly (but by no means exclusively) with passerines, and now thought to be linked to a poecivirus. AKD usually produces abnormally long and generally crossed mandibles, whereas this bird has exceptionally short mandibles, and the deformation appears to be in line with the head, not twisted."

- Scott Weidensaul, author, naturalist, active field researcher of owls and hummingbirds; www.scottweidensaul.com

"In my opinion, a hummer with such extensive bill damage does not stand much of a chance though we usually do not know the outcome for sure. Even if the bird is able to lap some sugar water from a feeder, the tongue will dry out and it will be incapable of eating sufficient nectar. Additionally, the bird will often be unable to secure enough insect food to satisfy its protein requirements. We hate to see such situations, but they are a fact of life." - Nancy Newfield, master bander with more than 39 years banding experience; www.casacolibri.net

"Yes, deformed culmens [mandibles] are seen sometimes and are often the result of collisions. However, the kind of deformation you show here is quite different and possibly a disease process. One thing I can tell you in hopefulness, is that I have seen adults with terrible deformities doing well."

- Alison Moran, in charge master bander of "The Hummingbird Project", a citizen science study coordinated through Rocky Point Bird Observatory, Victoria, B.C.; www.rpbo.org

There seem to be several possible underlying causes for deformed mandibles based on comments received on my post:

- an accident that broke the bill, which is seen with some regularity (Lanny Chambers, Cathie Hutcheson, personal communication sited in this article);

- dislocation, birth defects or a viral infection that may cause the bill to twist (Scott Weidensaul and Bill Hilton Jr., personal communications in this article).

From the comments above and the adult male captured in Michigan, deformed bills are observed when:

- numbers of hummingbirds banded are in of sufficient numbers (Cathie Hutcheson);

- experience (Nancy Newfield);

- contact with other hummingbird banders (Lanny Chambers).

Of note and possible interest is that an internet search of "hummingbird deformed bill" resulted in a list of postings for RTHU with deformed bills, dating back to 1998, with broken and twisted mandibles like in the photographs of Michigan and Alabama hummingbirds shown in this article (Figures 5 and 6). The reports came from Texas, Pennsylvania and Alabama. This is not surprising given that the majority of RTHU banders live in the United States. There were 67 Canadian permitted hummingbird banders in 2016 (pers. com Louise 


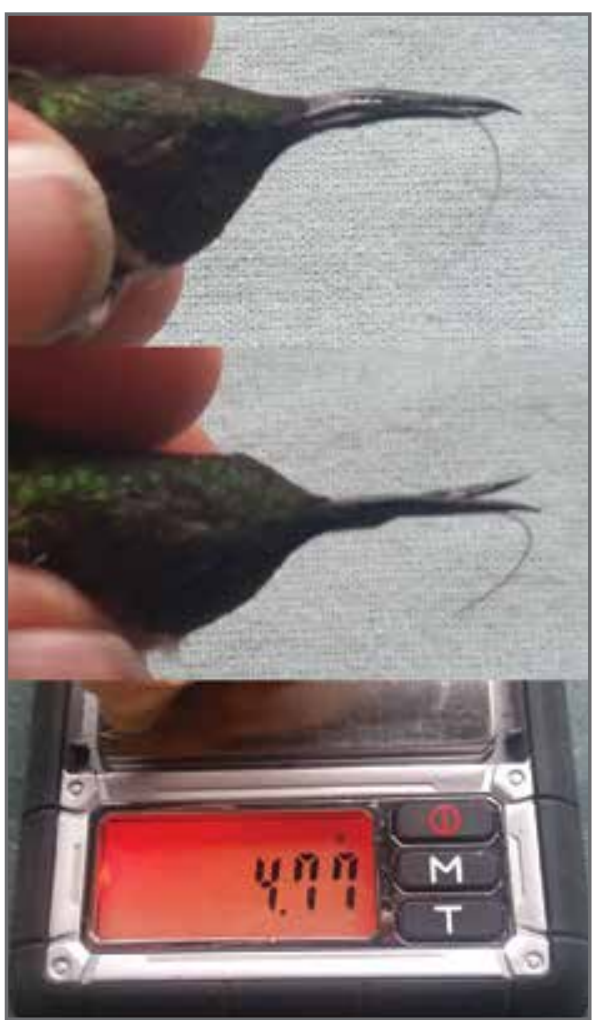

FIGURE 6. Adult male Ruby-throated Hummingbird from Michigan. Photo credit: Allen T. Chartier

Laurin, CWS Banding Office Ottawa, ON) versus 267 permitted hummingbird banders in the United States (pers. com. Bruce Peterjohn, Chief Bird Banding Lab, Laurel, MD).

The good news is that hummingbirds with deformed bills can survive for a surprisingly long time - over a year - as suggested by Cathie Hutcheon and Alison Moran. In addition, Allen Chartier in Michigan caught an adult male with at twisted bill, which suggests that the Michigan RTHU has survived at least one year and had migrated south to a wintering area, returning north the following spring. However, Nancy Newfield and Lanny Chambers both have a more pragmatic view that these hummingbirds with deformed bills don't survive long after fledging.

It appears that the degree of bill deformity may affect survival of fledglings. The fledgling caught north of Blaine Lake had survived possibly because an attentive mother had fed him. He was disheveled, feathers were unkept and unpreened when observed on August 20. It regained strength after being hand fed and with subsequent feedings at a feeder. The tongue was straight, extending beyond the mandibles but didn't appear dead or dried and withered. This is contrary to the tongue in the two RTHUs from Alabama and Michigan, in which photographs show a misshaped tongue outside of the mandibles. Note that I did not band the hummingbird north of Blaine Lake.

The question was asked if the Saskatchewan deformed bill hummingbird should have been euthanized. I was not interested in ending the life of a bird that was struggling and a survivor given what I observed in the four hours of banding. This hummingbird had returned to feed five times and apparently gained strength over the four hours of observation.

Finally, I found it interesting that the three RTHU in the photographs in this article are all males.

I would like to say that I have no special training, other than that to band hummingbirds, or expertise to explain the above information, observations and comments. I am fortunate to have had this RTHU with a deformed bill appear at a banding site, the site host notify me that a strange looking RTHU had arrived, and know enough to catch the RTHU in question and closely examine it. These led to questions and internet searches to learn more about deformed bills in hummingbirds and birds in general.

\section{Acknowledgements}

I would like to acknowledge considerable help from Phil Taylor, retired CWS biologist, who recorded the details of each banded hummingbird during the August 20 banding session, photographed the RTHU with the deformed mandible, conducted online searches for disease
As a sidebar to this article is $A K D$, avian keratin disorder. This disorder was reported to have been observed primarily in Alaskan Black-capped Chickadees (BCCH) and in 30 species of wild birds, at miniscule levels, all in Alaska'. Subsequently, AKD has appeared in the Pacific Northwest and the United Kingdom. Further investigation of affected BCCH in Alaska resulted in identification of a novel picornavirus in 19/19 affected $\mathrm{BCCH}^{2}$. An internet search for "hummingbird deformed bill" resulted in numerous sites, one all pictures of hummingbirds, text reports of deformed bill hummingbirds from as early as 1998. The causative agent(s) ranged from viral infections found in contaminated feeders, collisions with objects resulting in mandible breaks, AKD to unexplained causes.

reports and AKD in Alaska Blackcapped Chickadees, offered valuable comments on the wording of this article, discussed what we observed and helped to determine whether this observation was important enough to report to the hummingbird banding community and birders in general. Thanks as well to those who responded on Humband offering their thoughts and observations, some of which are reported above. Finally, thank you to the Blue Jay editor, an anonymous reviewer, and to Don Rohs, brother-in-law and retired English teacher, who all provided many helpful suggestions to clarify what was reported in this article.

1. Handel, C.M., et all. 2010. Epizootic of beak deformities among wild birds in Alaska: an emerging disease in North America? Auk 127:882-898. http://dx.doi.org/10.1525/ auk.2010.1011.

2. Zlyberberg, M. et all. 2016. Novel picornavirus with avian keratin disorder in Alaskan birds. https://mbio.asm.org/content/ mbio/7/4/e00874-16.full.pdf 